\title{
Risk Factors Associated with Different Stages of Atherosclerosis in Colombian Patients with Rheumatoid Arthritis
}

\author{
Adriana Rojas-Villarraga, MD, ${ }^{*}$ Oscar-Danilo Ortega-Hernandez, MD, ${ }^{\dagger}$ \\ Luis F. Gomez, MD ${ }^{\ddagger}$ Aryce L. Pardo, BSc, ${ }^{\circledR}$ Silvia López-Guzmán, MD, ${ }^{\mathbf{g}}$ \\ Camila Arango-Ferreira, ${ }^{\|}$Maria-Eugenia Hincapie, RN, MSc, ${ }^{\dagger}$ \\ Juan F. Betancur, "Ricardo Pineda-Tamayo, MD, ${ }^{* *}$ \\ Francisco J. Diaz, PhD, ${ }^{\dagger \dagger}$ and Juan-Manuel Anaya, $\mathrm{MD}^{\ddagger \neq}$
}

\begin{abstract}
Objectives: Rheumatoid arthritis (RA) is associated with an increased prevalence of cardiovascular disease (CVD). Since atherosclerosis development is a gradual process of damage inside the artery wall, and the phenotype-genotype correlation of complex diseases may vary depending on ethnicity, we sought to investigate the influence of clinical features, routine inflammatory markers, and the genetic component of RA on different stages of atherosclerosis in northwestern Colombian patients with RA. Methods: A group of 140 patients with RA were enrolled in this study. All patients underwent a noninvasive evaluation of endothelial function by flow-mediated vasodilation (FMV) and an assessment of carotid intima-media thickness (IMT) by high-resolution B-mode ultrasonography. The patients were classified into 3 categories: endothelial dysfunction (FMV $<5 \%$ ), increased IMT $(0.91-1.29 \mathrm{~mm})$, and plaque (IMT $>1.30 \mathrm{~mm}$ ). The risk of being in each category was assessed by investigating traditional and nontraditional cardiovascular risk factors. For each stage of atherosclerosis development, we searched for nontraditional risk factors that were significantly associated with the stage after adjusting for traditional risk factors and current age.

Results: Rheumatoid factor seropositivity was significantly associated with endothelial dysfunction (adjusted odds ratio, $A O R=3.0)$. A duration of $R A>10$ years $(A O R=29.0)$ and being a carrier of an HLA-DRB1 shared epitope allele $(A O R=4.8)$ were associated with atherosclerotic plaque. No association of extra-articular manifestations, anticyclic citrullinated peptide (anti-CCP3) antibodies, and tumor necrosis factor -308 polymorphism with CVD was found.

Conclusions: Our results reveal the presence of RA-related risk factors for CVD which act independently of traditional risk factors. These factors can be used by clinicians to predict CVD in RA patients, and this data should assist in the development of public health policies in our population for the improvement of patient outcomes.
\end{abstract}

(C) 2008 Elsevier Inc. All rights reserved. Semin Arthritis Rheum 38:71-82

\footnotetext{
*Assistant Researcher, Cellular Biology and Immunogenetics Unit (CBIGU), Corporación para Investigaciones Biológicas (CIB), Medellín, Colombia; School of Medicine, Universidad del Rosario (UR), Bogotá, Colombia; and School of Medicine, Universidad Pontifícia Bolivariana (UPB), Medellín, Colombia.

$\dagger$ Assistant Researcher, Cellular Biology and Immunogenetics Unit (CBIGU), Corporación para Investigaciones Biológicas (CIB), Medellín, Colombia

$\$$ Chief, Vascular Laboratory-Vasculab, Clinica Medellín, Medellín, Colombia.

§Assistant Researcher, Cellular Biology and Immunogenetics Unit (CBIGU), Corporación para Investigaciones Biológicas (CIB), Medellín, Colombia; and Department of Statistics, Universidad Nacional de Colombia (UNALM), Medellín, Colombia.

ๆAssistant Researcher, Cellular Biology and Immunogenetics Unit (CBIGU), Corporación para Investigaciones Biológicas (CIB), Medellín, Colombia; and School of Medicine, Universidad del Rosario (UR), Bogotá, Colombia.

|Medical student, School of Medicine, Universidad Pontifícia Bolivariana (UPB), Medellín, Colombia.

**Assistant Researcher, Cellular Biology and Immunogenetics Unit (CBIGU), Corporación para Investigaciones Biológicas (CIB), Medellín, Colombia ; and School of Medicine, Universidad Pontifícia Bolivariana (UPB), Medellín, Colombia.

† Associate Professor, Department of Statistics, Universidad Nacional de Colombia (UNALM), Medellín, Colombia.

\$\$Professor of Medicine and Chief, Cellular Biology and Immunogenetics Unit (CBIGU), Corporación para Investigaciones Biológicas (CIB), Medellín, Colombia; and School of Medicine, Universidad del Rosario (UR), Bogotá, Colombia.

Address reprint requests to: Juan-Manuel Anaya, MD, Corporación para Investigaciones Biológicas, Cra. 72A-78B-141, Medellín, Colombia. E-mail: anayajm@gmail.com.
} 
Keywords: rheumatoid arthritis, cardiovascular disease, endothelial dysfunction, intima-media thickness, atherosclerotic plaque, HLA, TNF, rheumatoid factor, anti-CCP antibodies, extra-articular manifestations

$\mathrm{I}$ schemic heart disease secondary to atherosclerosis is the most prevalent cause of death associated with cardiovascular disease (CVD) in patients with rheumatoid arthritis (RA) (1-3). Traditional risk factors such as dyslipidemia, smoking, increased waist circumference, and old age (4-6), and nontraditional risk factors such as extra-articular manifestations, swollen joint count, autoantibody levels, C-reactive protein (CRP), and other inflammatory markers have been implicated in accelerated atherosclerosis in these patients (7-10). Atherosclerosis is a process of gradual inflammation inside the artery wall. It begins with a change in the endothelium phenotype, followed by artery wall thickening, and finally, by the appearance of atherosclerotic plaque (11-13). Carotid intima-media thickness (IMT) is a measurement that is used to detect changes in the thickness of the artery wall secondary to the development of atherosclerosis (14). There is strong evidence supporting an increased carotid IMT in patients with RA (15-17). Increased carotid artery IMT has also been reported in long-term treated RA patients without clinically evident CVD or cardiovascular risk factors (18). Therefore, it is important to investigate the risk factors associated with different stages of atherosclerosis development since knowledge of these factors may help to improve prevention and treatment of CVD in RA patients. In addition, since RA patients may have impaired endothelial function before entering an early stage of atherosclerosis $(19,20)$, the evaluation of endothelial function through flow-mediated vasodilation (FMV) in the brachial artery may be helpful in detecting initial pathological changes in the artery wall and, therefore, in assessing early cardiovascular risk in these patients (21-23).

The mechanisms and risk factors influencing atherosclerotic plaque formation in patients with autoimmune diseases, such as RA, are not fully understood (24-26). A genetic feature that has been consistently associated with $\mathrm{RA}$ is the presence of $H L A-D R B 1$ alleles, which also have been implicated in RA disease severity and atherosclerosis development (27-30). Some tumor necrosis factor- $\alpha$ $(T N F)$ gene polymorphisms have been associated with susceptibility to RA $(31,32)$. However, it is not clear whether these polymorphisms are also associated with vascular damage in RA patients. The $T N F$ gene influences body weight homeostasis as well as insulin resistance, diabetes mellitus, lipid levels, hypertension, coagulation, endothelial damage, and inflammation (33-36).

Controversy exists as to whether $H L A-D R B 1$ polymorphisms affect susceptibility to RA, or affect disease severity and progression $(30,37,38)$. Moreover, the fact that more than 1 autoimmune disease may coexist in a single patient or in the same family supports the hypothesis of additional susceptibility genes $(39,40)$. Interestingly, 1 specific autoimmune disease (ie, RA) may be present in various members of a nuclear family, the so-called familial autoimmune disease, and different autoimmune diseases may occur in the relatives of a patient with RA (ie, familial autoimmunity) (41). These facts reinforce the polygenic character of RA (42).

Since the phenotype and genotype of complex diseases may vary depending on ethnicity, we sought to investigate the potential contribution of clinical RA features, routine inflammatory markers, and the genetic component to the development of atherosclerosis in northwestern Colombian patients with RA, controlling for potential confounders such traditional CVD risk factors $(43,44)$. Special attention was given to the different stages of atherosclerosis development. Since in practice the clinician may prefer to assess only 1 or a few inflammatory markers and/or genetic factors to predict CVD risk, we searched for those variables that may, by themselves and independently of traditional CVD risk factors, be predictors of increased atherosclerosis risk. This may be a more sensible approach than searching for predictors that can be used only when the clinician has access to a large number of other nontraditional predictors. An attempt was also made to answer the question of whether or not the presence of familial autoimmunity confers additional susceptibility to atherosclerosis in RA patients.

\section{METHODS}

\section{Study Population}

Consecutive RA patients attending the Clinical Immunology and Rheumatology Unit at the "Clínica Universitaria Bolivariana-Corporación para Investigaciones Biológicas" at Medellín, and fulfilling the American College of Rheumatology classification criteria were included (45). This study was undertaken between 2006 and 2007 and conducted in compliance with the 1993 Act 008430 by the Ministry of Health of the Republic of Colombia. The institutional review board of the "Corporación para Investigaciones Biológicas” approved the study design.

Age at RA onset was defined as the age at which patients began to suffer from pain, morning stiffness, and inflammation of hand and/or foot joints in a symmetrical fashion. Familial autoimmunity was defined as the presence of any diagnosed autoimmune disease in another member of the patient's nuclear family (46). Autoimmune hypothyroidism was diagnosed when there was a thyroid-stimulating hormone level $>5.0 \mathrm{IU}$, or evidence of thyroid hormone replacement because of primary hypothyroidism together with the presence of antithyroid peroxidase 
or antithyroglobulin antibodies. Patients with a history of acute myocardial infarction or stroke were not included in the sample to avoid an overestimation bias, because such patients could have high IMT values and low FMV. The patients underwent a detailed, clinical global examination that included an assessment of disease activity based on Disease Activity Score 28 (DAS 28) (47), and an overall assessment of quality of life based on the Multidimensional Health Assessment Questionnaire (48). Patients with a DAS 28 score $>3.2$ were considered to have active disease (49). Relevant laboratory variables associated with RA activity were tested: erythrocyte sedimentation rate (ESR), hemoglobin levels, white blood cell count, platelet count, and serum high sensitive CRP levels. Rheumatoid factor (RF) was measured by turbidimetry (Beckman, Brea, CA); titers $>40 \mathrm{U} / \mathrm{mL}$ were considered positive. Third-generation anticyclic citrullinated peptide (antiCCP3) antibodies were measured by an enzyme-linked immunosorbent assay kit (QUANTA-Lite, INOVA, San Diego, CA) according to the manufacturer's protocol; titers $>60$ U were considered positive (50). Serum levels of total cholesterol, triglycerides, high-density lipoprotein cholesterol, low-density lipoprotein cholesterol (LDL), and glucose were determined by using standard methods (Enzyme Assay Kit, Roche Diagnostics, Indianapolis, IN).

\section{TNF and HLA-DRB1 Genotyping}

Genomic DNA was extracted from $10 \mathrm{~mL}$ of an EDTAanticoagulated blood sample using the standard salting out technique. Genotyping for the TNF single nucleotide polymorphism (SNP) at -308 position was performed by a polymerase chain reaction as previously described (51). This SNP was investigated because some studies suggest that it may influence the risk of developing $\mathrm{RA}$ in Latin-Americans (including Colombians) (30). $H L A-D R B 1$ typing was done by reverse dot-blot hybridization of the polymerase chain reaction products (Inno-LiPA assay, Innogenetics, Ghent, Belgium) as described elsewhere (52). Genetic susceptibility to RA is associated with certain $H L A-D R B 1$ alleles encoding a similar sequence motif called the "shared epitope" (SE), which spans amino acid positions 70 to 74 in the third diversity region of the outermost domain of the HLA-DRB1 molecule (53). This SE is encoded mainly by the HLA-DRB1 *0101, *0102, *0401, *0404, ${ }^{*} 0405,{ }^{*} 0408,{ }^{*} 0409,{ }^{*} 0410,{ }^{*} 1402$ and ${ }^{*} 1001$ alleles. Also, HLA-DRB1 *0103, *0402, *1102, *1103, *1301, ${ }^{*} 1302$ and ${ }^{*} 1304$ alleles encode the DERAA sequence at the same positions, which has been shown to confer protection against RA development and severity (30,54-57). Hence, $H L A-D R B 1$ status was categorized according to the presence or absence of the $S E$ and DERAA motifs.

\section{Cardiovascular Risk Factors Assessment}

Patients were assessed for traditional CVD risk factors including current age ( $>45$ years for men and $>55$ years for women) (58-61), hypertension (defined as having a blood pressure $>140 / 90 \mathrm{~mm} \mathrm{Hg}$ or using antihypertensive medication) (62), diabetes mellitus [defined as having a fasting plasma glucose level $>7 \mathrm{mmol} / \mathrm{L}(126 \mathrm{mg} / \mathrm{dL})$ or taking antidiabetic medication at the time of the assessment] (63). A diagnosis of dyslipidemia was given when hypercholesterolemia (having a fasting plasma total cholesterol $>200 \mathrm{mg} / \mathrm{dL}$ ), low high-density lipoprotein cholesterol $(<40 \mathrm{mg} / \mathrm{dL})(58,64)$, hypertriglyceridemia $(>150 \mathrm{mg} /$ $\mathrm{dL})$, or elevated LDL cholesterol $(>100 \mathrm{mg} / \mathrm{dL})$ was present. Current hemoglobin $<12 \mathrm{~g} / \mathrm{dL}$ established a diagnosis of anemia. The fact of being smoker or having been a smoker (ever smoking) and history of premature coronary heart disease (CHD) in first-degree relatives were also assessed in all patients as previously described (65). Systolic and diastolic blood pressures were measured twice with at least 15 minutes between measurements and the averages were recorded. Patients were clinically evaluated for the presence of CVD including heart and peripheral vascular disease (66). We estimated CHD risk using the Framingham Heart Study prediction score sheets. Separate score sheets were used for men and women. The Framingham score provides an estimate of total CVD risk over the course of 10 years (67).

\section{Anthropometric Measurements}

A body mass index (BMI) $>30 \mathrm{~kg} / \mathrm{m}^{2}$ was considered abnormal (68). The patients were assessed for the presence of the metabolic syndrome by using the definition from the National Cholesterol Education Program Adult Treatment Panel III (69). Abnormal values of waist circumference ( $\geq 102 \mathrm{~cm}$ for men, $\geq 88 \mathrm{~cm}$ for women) and waist-to-hip ratio (WHR; $>0.9$ for men, $>0.85$ for women) were considered indicators of abdominal obesity, which is the most prevalent manifestation of metabolic syndrome, a marker of dysfunctional adipose tissue and is also associated with increased risks of type 2 diabetes and CVD (70). Waist circumference was measured around the narrowest point between ribs and hips after exhaling when viewed from the front. Hip circumference was measured at the point of maximum extension of the buttocks when viewed from the side (71). Abnormal WHR values are consistent with National Cholesterol Education Program Adult Treatment Panel III and World Health Organization definitions (72). The above measurements were used to find the most reliable predictors of vascular involvement in patients with RA.

\section{Assessment of Carotid Intima-Media Thickness}

Ultrasound measurements of IMT of the common carotid artery were performed by an expert (LFG) who was 
blind to patients' clinical records. High-resolution, 2-dimensional images were obtained using an ultrasound machine (Agilent-Hewlett-Packard, Santa Clara, CA). A 7.5-MHz linear-array transducer with an axial resolution of $0.15 \mathrm{~mm}$ and a penetration depth from 1.0 to $5.0 \mathrm{~cm}$ was used (73). The patient rested on the examination table for 15 minutes before the initial carotid ultrasound scan. The measurement was applied to the far wall of the right and left carotid arteries. Following Salonen and Salonen (74), a B-mode screening method was used with electronic calipers within $10 \mathrm{~mm}$ proximal to the common carotid bifurcation in a temperature-controlled room $\left(22^{\circ} \mathrm{C}\right.$ to $\left.24^{\circ} \mathrm{C}\right)(75)$. Ultrasound images were recorded on videotape (Sony MD 385). IMT was measured at the site of greatest thickness and at 2 additional points: $1 \mathrm{~cm}$ upstream and $1 \mathrm{~cm}$ downstream from this site. The average of these 3 values was computed. In keeping with previous reports, patients with carotid IMT less than 0.60 $\mathrm{mm}$ were considered to be free of atherosclerosis. On the other hand, since carotid IMT greater than $0.90 \mathrm{~mm}$ is included among the definitions of subclinical organ damage (76), we established 3 different categories: carotid IMT values less than $0.90 \mathrm{~mm}$; those between 0.91 and 1.29 considered as having severe subclinical atherosclerosis (SSA); and plaques if values were equal to or greater than $1.30 \mathrm{~mm}$. The reproducibility of the IMT was evaluated by taking 2 measurements 1 month apart on 12 volunteers, obtaining an intraclass correlation of 0.98 .

\section{Noninvasive Evaluation of Endothelial Function}

To detect endothelial dysfunction, brachial FMV was assessed by noninvasive ultrasound. The assessment was made by the same examiner who performed the ultrasound measurements of IMT. The brachial artery diameter was measured on B-mode imaging using a high-resolution $(7.5 \mathrm{MHz})$ linear array transducer. During the diastolic phase, a basal diameter was measured from the anterior to posterior interface between the media and adventitia ("m line") at a fixed distance (77). A pneumatic tourniquet placed around the forearm distal to the target artery was inflated to a pressure of $250 \mathrm{~mm} \mathrm{Hg}$ and inflation was held for 5 minutes. Increased flow was then induced by sudden cuff deflation. Twenty seconds later, the brachial artery diameter was measured. Fifteen minutes later, another resting scan was recorded to confirm vessel recovery. This method detects diameter changes of 0.1 to $0.2 \mathrm{~mm}$ (78). The diameter change caused by FMV was expressed as the percentage change in diameter relative to the basal diameter. A percentage change $\geq 5 \%$ after the reactive hyperemia indicated a reactive normal artery (79). For patients under current antihypertensive therapy, the therapy was discontinued a few days before evaluating endothelial function.

\section{Statistical Analysis}

Age at RA onset, disease duration, and current age were categorized into groups determined by quartiles. Endothelial dysfunction, increased IMT (SSA), and the presence of carotid plaque were used as dependent variables. First, univariate analyses searching for the association between traditional CVD risk factors and endothelial dysfunction were investigated using $\chi^{2}$ tests or Fisher's exact tests when the factors were dichotomous, or $t$-tests for mean differences when the factors were continuous. Similar univariate analyses were performed for the nontraditional risk factors. Next, for each nontraditional risk factor that was significantly associated with endothelial dysfunction in univariate analyses, a multivariate logistic regression model that included endothelial dysfunction as the dependent variable was fit. As independent variables, the model included the nontraditional variable, the traditional variables that were significantly associated with endothelial dysfunction in univariate analyses, and current age. (Current age was controlled for since it was considered a potential confounding factor.) Analogous analyses were made by using increased IMT (SSA) or the presence of atherosclerotic plaque in place of endothelial dysfunction. $P$ values $<0.05$ were considered significant. Odds ratios (ORs) that measured the effect size of risk factors on endothelial dysfunction, IMT (SSA), or the presence of atherosclerotic plaque were computed together with their 95\% confidence intervals (CIs). The adequacy of logistic models was assessed using the Hosmer-Lemeshow goodness-of-fit test. All reported logistic models fit well. Statistical analyses were performed by using the Statistical Package for the Social Sciences (SPSS, v.15, Chicago, IL).

\section{RESULTS}

One hundred forty patients were included. Their general findings related to RA are described in Table 1. Patients were between 26 and 78 years old and all patients belonged to the same ethnic group. The most prevalent allele was HLA$D R B 1^{*} 0404$, which was present in $23 \%(30 / 132)$ of the patients. Expected SE-amino acid sequences were available in 132 patients and distributed as follows: QKRAA (DRB1*0401), 2\% (3/132); QRRAA (DRB1*0404, ${ }^{*} 0405$, ${ }^{*} 0408$, and $\left.{ }^{*} 1402\right), \quad 42 \% \quad(55 / 132)$; and RRRAA (DRB $\left.1{ }^{*} 0101,{ }^{*} 0102,{ }^{*} 1001\right), 4 \%(5 / 132)$. The protective sequence, DERAA, was found in $10 \%(13 / 132)$ of the patients. All patients were receiving a standard therapeutic regimen consisting of methotrexate $(<20 \mathrm{mg} / \mathrm{wk})$ plus regular folic acid supplementation $(7 \mathrm{mg} / \mathrm{wk})$, prednisone $(<10$ $\mathrm{mg} / \mathrm{d})$, chloroquine $(250 \mathrm{mg} / \mathrm{d})$, and sulfasalazine $(1.5 \mathrm{~g} / \mathrm{d})$. Twenty-one percent $(30 / 140)$ of the patients were receiving biological therapy.

The prevalence of endothelial dysfunction, increased IMT (SSA), and the presence of atherosclerotic plaque were $31 \%(44 / 140), 54 \%(75 / 140)$, and 7\% (10/140), respectively. This suggests that FMV and IMT reflect distinct and independent stages in the complexity of atherosclerosis de- 
Table 1 Clinical Characteristics of 140 Patients with Rheumatoid Arthritis

\begin{tabular}{|c|c|}
\hline & Mean $\pm S D$ \\
\hline Age at RA onset & $40.5 \pm 12.3$ \\
\hline Current age $(y)$ & $54.2 \pm 11.3$ \\
\hline Duration of arthritis (y) & $13.8 \pm 8.5$ \\
\hline Swollen joints count & $5.7 \pm 5.9$ \\
\hline $\mathrm{HAQ}$ & $1.7 \pm 0.7$ \\
\hline Patient global assessment (VAS) & $4.6 \pm 2.9$ \\
\hline Physician global assessment (VAS) & $4.1 \pm 2.8$ \\
\hline DAS 28 & $4.4 \pm 1.4$ \\
\hline Current RF antibody titers & $198.8 \pm 326.1$ \\
\hline Current anti-CCP antibody titers & $260.7 \pm 181.1$ \\
\hline Hemoglobin $(\mathrm{mg} / \mathrm{dL})$ & $13 \pm 1.5$ \\
\hline Total leukocyte count $\left(\times 10^{3} / \mu \mathrm{L}\right)$ & $8 \pm 2.3$ \\
\hline $\begin{array}{l}\text { Polymorphonuclear cell count } \\
\qquad\left(\times 10^{3} / \mu \mathrm{L}\right)\end{array}$ & $5.1 \pm 1.9$ \\
\hline Lymphocytes count $\left(\times 10^{3} / \mu \mathrm{L}\right)$ & $2.3 \pm 0.8$ \\
\hline $\operatorname{ESR}(\mathrm{mm} / \mathrm{h})$ & $38.9 \pm 25.1$ \\
\hline \multirow[t]{2}{*}{ CRP $(\mathrm{mg} / \mathrm{L})$} & $5.9 \pm 15$ \\
\hline & Percentage/Numbers \\
\hline Female & $84(117 / 140)$ \\
\hline Anemia & $28(39 / 140)$ \\
\hline EAM & $43(60 / 140)$ \\
\hline Family history of autoimmunitya & $21(29 / 140)$ \\
\hline Autoimmune thyroid disease $\mathrm{a}^{\mathrm{a}}$ & $22(31 / 140)$ \\
\hline $\mathrm{RF}(+)$ & $63(85 / 134)$ \\
\hline Anti-CCP antibody $(+)$ & $78(73 / 94)$ \\
\hline Methotrexate & $94(131 / 140)$ \\
\hline Steroid therapy & $94(131 / 140)$ \\
\hline Chloroquine & $61(86 / 140)$ \\
\hline TNF inhibitor & $21(30 / 140)$ \\
\hline HLA-DRB1 SE & $46(60 / 132)$ \\
\hline TNF SNP-308 GG & $58(76 / 132)$ \\
\hline TNF SNP-308 AG & $26(34 / 132)$ \\
\hline TNF SNP-308 AA & $1(2 / 132)$ \\
\hline Presence of SE (single copy) & $37(49 / 132)$ \\
\hline Presence of SE in both alleles & $8(11 / 132)$ \\
\hline \multicolumn{2}{|c|}{$\begin{array}{l}\text { RA, rheumatoid arthritis; RF, rheumatoid factor; Anti-CCP, anti } \\
\text { cyclic citrullinated peptide antibodies; SE, shared epitope; EAM } \\
\text { extra-articular manifestations; HAQ, Health Assessment Ques } \\
\text { tionnaire score; ESR, erythrocyte sedimentation rate; CRP, C-re } \\
\text { active protein; DAS 28, disease activity score 28; VAS, visua } \\
\text { analog scale; TNF, tumor necrosis factor alpha; TNF SNP-308 } \\
\text { single nucleotide polymorphism at position -308 in gene pro- } \\
\text { moter. } \\
\text { aSee Patients and Methods for definition. }\end{array}$} \\
\hline
\end{tabular}

velopment (79). Overall, 36\% (51/140) of the patients had a 10 -year risk of a cardiovascular event that was $<5 \% ; 27 \%$ $(38 / 140)$ had a risk of 5 to $10 \% ; 24 \%(34 / 140)$ had a risk of 11 to $15 \%$; and $12 \%(17 / 140)$ had a 10 -year risk $>15 \%$. Additional cardiovascular findings are shown in Table 2.

\section{Univariate Analyses of Traditional Risk Factors for Cardiovascular Disease}

Having elevated triglycerides and elevated LDL cholesterol levels were both significantly associated with endothelial dysfunction (Table 3). Abnormal waist circumfer-
Table 2 Cardiovascular Characteristics of 140 Patients with Rheumatoid Arthritis

\begin{tabular}{|c|c|}
\hline Characteristics & Mean $\pm S D$ \\
\hline $\mathrm{BMI}\left(\mathrm{kg} / \mathrm{m}^{2}\right)$ & $25.5 \pm 4.7$ \\
\hline Waist circumference ${ }^{a}$ & $90.7 \pm 12.7$ \\
\hline WHR & $0.9 \pm 0.2$ \\
\hline Systolic blood pressure $(\mathrm{mm} \mathrm{Hg})$ & $130.7 \pm 16.6$ \\
\hline Diastolic blood pressure $(\mathrm{mm} \mathrm{Hg})$ & $82.2 \pm 10.4$ \\
\hline Total cholesterol $(\mathrm{mg} / \mathrm{dL})$ & $204.1 \pm 41.6$ \\
\hline HDL cholesterol (mg/dL) & $52.6 \pm 13.4$ \\
\hline Triglycerides (mg/dL) & $141.9 \pm 62.3$ \\
\hline LDL cholesterol (mg/dL) & $123.4 \pm 36.1$ \\
\hline Creatinine $(\mathrm{mg} / \mathrm{dL})$ & $0.8 \pm 0.2$ \\
\hline Glycemia & $90.8 \pm 27.8$ \\
\hline $\begin{array}{l}\text { Ten-year risk of a cardiovascular } \\
\text { event }^{\mathrm{a}}\end{array}$ & $7.9 \pm 6.3$ \\
\hline Brachial diameter change (\%) & $9.3 \pm 8.2$ \\
\hline IMT (mm) & $0.91 \pm 0.24$ \\
\hline & Percentage/Numbers \\
\hline Metabolic syndrome ${ }^{a}$ & $44(61 / 140)$ \\
\hline Diabetes $^{a}$ & $4(6 / 140)$ \\
\hline Ever smoking & $44(61 / 140)$ \\
\hline First-degree relative with $\mathrm{CHD}^{\mathrm{a}}$ & $16(22 / 140)$ \\
\hline Current hypertension & $41(57 / 140)$ \\
\hline Dyslipidemia $^{a}$ & $35(49 / 140)$ \\
\hline Current antihypertensive therapy & $32(45 / 140)$ \\
\hline Current lipid-lowering therapy & $13(18 / 139)$ \\
\hline $\begin{array}{l}\text { History of hormone replacement } \\
\text { therapy }\end{array}$ & $7(10 / 140)$ \\
\hline Physical inactivity & $85(119 / 140)$ \\
\hline FMV (change $<5 \%)^{\mathrm{a}}$ & $31(44 / 140)$ \\
\hline $\begin{array}{l}\text { Increased IMT (severe subclinical } \\
\text { atherosclerosis) }^{\text {a }}\end{array}$ & $54(75 / 140)$ \\
\hline $\begin{array}{l}\text { Presence of atherosclerotic } \\
\text { plaque }^{\text {a }}\end{array}$ & $7(10 / 140)$ \\
\hline Abnormal waist circumference ${ }^{a}$ & $56(78 / 140)$ \\
\hline Abnormal WHR ${ }^{a}$ & $83(116 / 140)$ \\
\hline Abnormal BMla & $16(23 / 140)$ \\
\hline Cholesterol levels $>200 \mathrm{mg} / \mathrm{dL}$ & $56(79 / 140)$ \\
\hline Low HDL cholesterola & $15(21 / 140)$ \\
\hline LDL cholesterol $>100 \mathrm{mg} / \mathrm{dL}$ & $76(106 / 140)$ \\
\hline Triglycerides $\geq 150 \mathrm{mg} / \mathrm{dL}$ & $37(52 / 140)$ \\
\hline Abnormal fasting glucose levels ${ }^{a}$ & $17(24 / 140)$ \\
\hline $\mathrm{CRP}>5 \mathrm{mg} / \mathrm{L}$ & $70(89 / 128)$ \\
\hline
\end{tabular}

BMI, body mass index; WHR, waist-to-hip ratio; HDL, highdensity lipoprotein; LDL, low-density lipoprotein; FMV, flow mediated vasodilation; CHD, coronary heart disease; IMT, intimamedia wall thickness; CRP, C-reactive protein.

aSee Patients and Methods for definition.

ence, abnormal WHR, and a Framingham risk score $>5 \%$ were significantly associated with increased IMT (SSA). Ever smoking was significantly associated with the presence of atherosclerotic plaque.

\section{Univariate Analyses of Nontraditional Risk Factors}

Having a positive RF was significantly associated with endothelial dysfunction (Table 4). In univariate analyses, 
Table 3 Traditional Risk Factors for Cardiovascular Disease Significantly Associated with Endothelial Dysfunction, Increased Intima-Media Thickness, and Atherosclerotic Plaque in RA Patients According to Univariate Analyses ${ }^{a}$

\begin{tabular}{|c|c|c|c|}
\hline & $\begin{array}{l}\text { dothelial Dysfunction } \\
\text { OR }(95 \% \mathrm{Cl})\end{array}$ & $\begin{array}{c}\text { Increased IMT } \\
(\mathrm{SSA})^{\mathrm{c}, \mathrm{d}} \text { OR }(95 \% \mathrm{Cl})\end{array}$ & $\begin{array}{c}\text { Presence of Atherosclerotic } \\
\text { Plaque OR }(95 \% \mathrm{CI})\end{array}$ \\
\hline Abno & - & $.3)$ & - \\
\hline Abnormal WHR & - & 1.3 to 8.9$)$ & - \\
\hline Triglycerides $\geq 150 \mathrm{mg} / \mathrm{dL}$ & 2.5 (1.2 to 5.3$)$ & - & - \\
\hline LDL cholesterol $>100 \mathrm{mg} / \mathrm{dL}$ & $2.6(1.0$ to 6.9$)$ & - & - \\
\hline Ever smoking & - & - & $32.4(1.9 \text { to } 565.7)^{f}$ \\
\hline Ten-year risk of a cardiovascular event $(\geq 5 \%)^{\mathrm{e}}$ & - & $4.4(2.0$ to 9.1$)$ & - \\
\hline \multicolumn{4}{|c|}{$\begin{array}{l}\text { RA, rheumatoid arthritis; OR, odds ratio; } \mathrm{Cl} \text {, confidence interval; IMT, increased intima-media thickness; WHR, waist-to-hip ratio; SSA, severe } \\
\text { subclinical atherosclerosis. } \\
\text { Only odds ratios that were significant at a } 0.05 \text { level of significance are reported. } \\
\text { aHypertension, having a first-degree relative with } \mathrm{CHD} \text {, hormone replacement therapy, diabetes, body mass index, total cholesterol, HDL } \\
\text { cholesterol, creatinine, and abnormal glycemia were not significantly associated with endothelial dysfunction, IMT (SSA), or presence of } \\
\text { atherosclerotic plaque. } \\
\text { bA diagnosis of current dyslipidemia was significantly associated with endothelial dysfunction }[\mathrm{OR}=3.0 ; 95 \% \mathrm{Cl}(1.4 \text { to } 6.2)] \text {. } \\
\text { cA diagnosis of current dyslipidemia was significantly associated with IMT (SSA) [OR = 2.1; } 95 \% \mathrm{Cl}(1.0 \text { to } 4.3)] \text {. } \\
\text { dA diagnosis of a metabolic syndrome was significantly associated with increased IMT (SSA) [OR }=3.1 ; 95 \% \mathrm{Cl}(1.5 \text { to } 6.2)] \text {. } \\
\text { eSee Patients and Methods for definition. } \\
\text { fNone of the never smokers had atherosclerotic plaque. }\end{array}$} \\
\hline
\end{tabular}

having low hemoglobin levels was a significantly protective factor for endothelial dysfunction. Late RA onset was significantly associated with both increased IMT (SSA) and the presence of atherosclerotic plaque. An arthritis duration $\geq 10$ years, having a familial autoimmunity, and being a carrier of 1 HLA SE allele were significantly associated with the presence of atherosclerotic plaque.

\section{Adjusted Effects of Nontraditional Risk Factors on the Different Stages of Atherosclerosis Development}

In a logistic regression analysis that adjusted for current age and potentially confounding traditional risk factors (having triglycerides $\geq 150 \mathrm{mg} / \mathrm{dL}$ and LDL cholesterol $>100 \mathrm{mg} / \mathrm{dL}$ ), RF seropositivity was significantly associated with an increased risk of endothelial dysfunction $(\mathrm{OR}=3.0, P=0.02$, Table 5$)$. In a similar analysis, having low hemoglobin levels was not significantly associated with endothelial dysfunction $(P=0.9)$. Even though a late RA onset was significantly associated with increased IMT (SSA) in univariate analyses, the association did not remain significant after adjusting for current age, abnormal WHR, and having a Framingham risk score $\geq 5 \%(P=0.5$, Table 5$)$.

After adjusting for potential confounders (current age and ever smoking), a late RA onset $(P=0.01$, OR $=$ $12.8)$, a duration of disease $\geq 10$ years $(P=0.003$, OR $=$ 29.0 ), and being a carrier of a single copy of HLA-DRB1 SE $(P=0.045, \mathrm{OR}=4.8)$ were significantly associated with an increased risk of atherosclerotic plaque (Table 5). Familial autoimmunity was not significantly associated with having atherosclerotic plaque $(P=0.3)$.

\section{DISCUSSION}

This study describes the prevalence of endothelial dysfunction and atherosclerosis in Latin-American patients with RA for the first time. The prevalences of diabetes and abdominal obesity in these RA patients were comparable

Table 4 Nontraditional Risk Factors Significantly Associated with Endothelial Dysfunction, Increased IMT, and Atherosclerotic Plaque in RA Patients According to Univariate Analyses

\begin{tabular}{|c|c|c|c|}
\hline & $\begin{array}{l}\text { Endothelial Dysfunction } \\
\text { OR }(95 \% \mathrm{Cl})\end{array}$ & $\begin{array}{l}\text { Increased IMT (SSA) } \\
\text { OR }(95 \% \mathrm{CI})\end{array}$ & $\begin{array}{c}\text { Presence of Atherosclerotic } \\
\text { Plaque OR }(95 \% \mathrm{CI})\end{array}$ \\
\hline Age at RA onset $>51$ years & - & $3.8(1.4$ to 10.2$)$ & $23.4(4.6$ to 118.6$)$ \\
\hline Duration of arthritis $(>10 \mathrm{y})$ & - & - & $6.0(1.2$ to 29.4$)$ \\
\hline $\mathrm{RF}(>40 \mathrm{IU})$ & $2.4(1.0$ to 5.4$)$ & - & - \\
\hline Current hemoglobin $<12 \mathrm{~g} / \mathrm{dL}$ & $0.31(0.12$ to 0.82$)$ & - & - \\
\hline Familial autoimmunity ${ }^{a}$ & - & - & $4.4(1.2$ to 16.5$)$ \\
\hline SE (single copy) & - & - & 4.5 (1.1 to 18.3$)$ \\
\hline \multicolumn{4}{|c|}{$\begin{array}{l}\text { OR, odds ratio; } \mathrm{Cl} \text {, confidence interval; RA, rheumatoid arthritis; IMT, increased intima-media thickness; SSA, severe subclinical atheroscle- } \\
\text { rosis; RF, rheumatoid factor; SE, shared epitope. } \\
\text { Only odds ratios that were significant at a } 0.05 \text { level of significance are reported. } \\
\text { aSee Patients and Methods for definition. }\end{array}$} \\
\hline
\end{tabular}


Table 5 Adjusted Odds Ratios for the nontraditional Variables that Were Significantly Associated with Endothelial Dysfunction, Increased IMT (Severe Subclinical Atherosclerosis), and Atherosclerotic Plaque in Univariate Analyses

\begin{tabular}{|c|c|c|}
\hline & $\mathrm{OR}^{\mathrm{a}}$ & \\
\hline \multicolumn{3}{|l|}{ Endothelial dysfunction } \\
\hline Positive RF $>40$ IU & $(1.2 \mathrm{t}$ & .02 \\
\hline $\begin{array}{l}\text { urrent hemoglobin } \\
<12 \mathrm{~g} / \mathrm{dL}\end{array}$ & $1.1^{\mathrm{b}}(0.40$ & \\
\hline MT (SSA) & & \\
\hline Age at RA onset $(>51 \mathrm{y})$ & $1.5^{c}(0.4$ & \\
\hline \multicolumn{3}{|l|}{$\begin{array}{l}\text { Presence of } \\
\text { atherosclerotic plaque }\end{array}$} \\
\hline Age at RA onset $(>51 \mathrm{y})$ & $12.8^{d}$ & 0.0 \\
\hline tis & (3.1 to 270.3 ) & 0.003 \\
\hline & $2.2^{\mathrm{d}}(0$. & 0.3 \\
\hline JL (J) & $4.8^{\mathrm{d}}(0.98$ & 0.04 \\
\hline \multicolumn{3}{|c|}{$\begin{array}{l}\text { OR, adjusted odds ratio; } \mathrm{Cl} \text {, confidence interval; RA, rheumatoid } \\
\text { arthritis; IMT, increased intima-media thickness; SSA, severe sub- } \\
\text { clinical atherosclerosis; RF, rheumatoid factor; SE, shared } \\
\text { epitope. } \\
\text { aThe adjustment was performed through logistic regression } \\
\text { analyses that controlled for current age and the traditional vari- } \\
\text { ables that were significantly associated with the dependent vari- } \\
\text { ables in univariate analyses. } \\
\text { bThe OR and its corresponding } \mathrm{Cl} \text { were adjusted for current } \\
\text { age and the traditional variables that were significantly associ- } \\
\text { ated with endothelial dysfunction in univariate analyses (triglyc- } \\
\text { erides } \geq 150 \mathrm{mg} / \mathrm{dL} \text { and LDL cholesterol } \times 100 \mathrm{mg} / \mathrm{dL} \text { ). } \\
\text { 'The OR and its corresponding } \mathrm{Cl} \text { were adjusted for current } \\
\text { age and the traditional variables that were significantly associ- } \\
\text { ated with IMT (SSA) in univariate analyses [abnormal waist-to- } \\
\text { hip ratio (WHR) and } 10 \text {-year risk of a cardiovascular event ac- } \\
\text { cording to the Framingham Risk Score ( } \geq 5 \% \text { )]. Since abnormal } \\
\text { WHR had a higher OR than waist circumference, the former was } \\
\text { included in the logistic model. } \\
\text { dThe OR and its corresponding Cl were adjusted for current } \\
\text { age and the traditional variable that was significantly associated } \\
\text { with presence of atherosclerotic plaque in univariate analyses, } \\
\text { ever smoking. }\end{array}$} \\
\hline
\end{tabular}

with those in healthy but younger Colombian volunteers (80). By contrast, hypercholesterolemia $(56 \%$ versus $17 \%$; OR $=6.15 ; 95 \% \mathrm{CI}, 3.86-9.81)$ and smoking $(44 \%$ versus $7 \%$; OR $=10.72 ; 95 \% \mathrm{CI}, 5.91-19.43)$ prevalences were significantly higher in the RA patients than in the healthy population (80).

An advantage of this study was that we analyzed patients at 3 different stages in the development of atherosclerosis: endothelial dysfunction, increased IMT (SSA), and the presence of atherosclerotic plaque. The evaluation of these stages allows a better description of the risk factors associated with atherosclerosis development in RA patients. However, this study represents a cross-sectional view of an ongoing process.

Our results confirm that endothelial dysfunction, which is considered an early stage of atherosclerosis, is associated with dyslipidemia, especially hypertriglyceridemia and elevated LDL cholesterol levels, both considered atherogenic risk factors (81-83).
Of the nontraditional risk factors, RF seropositivity was significantly associated with endothelial dysfunction after adjusting for hypertriglyceridemia, elevated LDL cholesterol levels, and current age. The odds of endothelial dysfunction in patients with a positive RF were 3 times higher than the odds in patients with a negative $\mathrm{RF}$, suggesting a strong association that is independent of traditional CVD risk factors. A recent study suggested that a positive RF is an independent risk factor for ischemic heart disease even in the general population (84). However, there is no biological explanation supporting an ethiopathogenic effect of RF on endothelial dysfunction. The association of a positive RF with endothelial dysfunction, however, may reflect a high degree of inflammation rather than an RF causal effect on atherosclerosis development $(85,86)$.

We found that an increased IMT was related to late RA onset ( $>51$ years) and abnormal abdominal adiposity but only in the univariate analyses. After adjusting for current age and a 10-year risk of a cardiovascular event $\geq 5 \%$ through a logistic regression model, these associations disappeared. This suggests that other risk factors that have not been studied could be associated with an increased IMT in our population. Nevertheless, measuring waist circumference instead of BMI alone is advisable, because individuals with selective excess of intra-abdominal or visceral adipose tissue are at a substantially higher risk of becoming insulin resistant and of developing metabolic syndrome. Those measurements can also be useful for the clinician to determine the CVD risk associated in patients with RA $(87,88)$.

A Framingham risk score $>5 \%$, which measures the total CVD risk over the course of 10 years, was associated with increased IMT in univariate analysis $(\mathrm{OR}=4.4)$, suggesting that it may be a good predictor of atherosclerosis development in RA patients. This finding demonstrates that clinical score predictors of total CVD risk in the general population as well as in RA patients may be useful tools for following up patients and designing early interventions (89).

After adjusting for current age and ever smoking, we found that both late RA onset (>51 years) and disease duration of more than 10 years were associated with development of atherosclerotic plaque. The finding that long disease duration was associated with the presence of atherosclerotic plaque confirms that RA is a risk factor for blood vessel deterioration that may act independently of traditional cardiovascular risk factors (90). In a previous study conducted in Spain, investigators also observed significantly longer disease duration in RA patients with plaque when compared with those RA patients without plaque (18). In this elegant study, in which RA patients lacked clinically evident CVD or classic cardiovascular risk factors, age and disease duration at the time of the ultrasonographic assessment were the best predictive factors of the development of severe morphologic expression of atherosclerotic disease (presence of carotid plaques) (18). 
Ever smoking was associated with the presence of atherosclerotic plaque in univariate analyses; this association was apparently strong but disappeared after adjusting for nontraditional risk factors. A family history of autoimmune diseases was not associated with the presence of atherosclerotic plaque after adjusting for current age and ever smoking.

After adjusting for current age and ever smoking, we found that the HLA-DRB1 SE was associated with a 5 -fold increased risk of having atherosclerotic plaque. HLA-DRB1 SE alleles influence the risk of developing RA in Colombians (91) as well as atherosclerosis in these patients. In keeping with these observations, a recent population-based study disclosed that in Northwestern Spanish patients with $R A H L A-D R B 1^{*} 04 \mathrm{SE}$ alleles and in particular $H L A-D R B 1^{*} 0404$ increased the risk of cardiovascular death (92). In our study, after adjusting for having a single $\mathrm{SE}$ allele, there was no significant association between ever smoking and the presence of atherosclerotic plaque. In other populations, smoking appears to be an important risk factor that increases IMT and accelerates atherosclerosis in RA patients (93-95).

In the present study, inflammatory markers such as CRP and ESR were not associated with any stage of atherosclerosis development in RA. However, CRP is a good indicator for inflammation as well as a predictive risk factor of CHD in healthy people $(96,97)$. In patients with autoimmune diseases, the interpretation of high levels of inflammatory markers is confounded by the correlation with systemic inflammation $(98,99)$. Prospective epidemiological studies have found associations between an increased risk of vascular deterioration and increased basal levels of cytokines such as IL-6, cell adhesion molecules such as soluble intercellular adhesion molecule 1 (ICAM-1) and P-selectin $(100,101)$, and of downstream acute-phase reactants such as CRP, fibrinogen, and serum amyloid A protein (102). Other studies suggest that the strength and chronicity of the inflammatory response measured by CRP levels correlates directly with the presence of atherosclerosis in patients with RA $(103,104)$. Moreover, a significantly increased risk of CV death was also associated with chronic inflammation determined by CRP and ESR (92).

No association was found between the TNF SNP -308 and the 3 stages of atherosclerosis. Previous studies found that the $T N F-308 G G$ genotype was protective against autoimmunity and that the $T N F-308 A$ allele was associated with an increased risk of RA (51). Neither the most prevalent $T N F$ genotype (GG) nor the less prevalent (GA) correlated with atherosclerosis in this study. This suggests that $T N F$ polymorphism is not a cardiovascular risk factor in our population of RA patients.

CVD are complex genetic diseases that cluster in families (105-109). There is evidence indicating the possibility of susceptibility genetic variants shared by RA and CVD $(110,111)$ as well as specific susceptibility loci for coronary artery disease that are independent of suscepti- bility loci for RA (112). Specific loci have been significantly associated with an abnormal BMI, hypertension, and elevated LDL cholesterol levels (112). Studies of patients with a strong family history of coronary artery disease confirmed that cardiovascular diseases cluster in families just as autoimmune diseases do $(113,114)$. In contrast to other reports (115), the current study did not find a significant association between a history of premature cardiovascular heart disease in patients' first-degree relatives and any stage of atherosclerosis development. Further identification of genetic loci associated with RA and its complications (ie, CVD) is warranted and should be translated into prediction of disease, understanding of disease physiopathological mechanisms, and early interventions to prevent premature coronary disease in RA patients.

Although the lack of prospective follow-up and inclusion of patients with longstanding disease could be considered as shortcomings of this study, our results indicate the presence of RA-related risk factors for CVD in our population, which act independently of traditional risk factors. We confirmed the influence of HLA-DRB1-SE on the risk of developing atherosclerotic plaque in RA. Prevention and treatment of CVD are essential not only to reduce mortality risk in RA but also to reduce the economic burden of the disease. In fact, CVD is the most important determinant of high costs associated with hospitalizations of patients with RA (116). These data point to the need for new public health policies to improve patient outcomes.

\section{ACKNOWLEDGMENTS}

We thank all participants in this study and our colleagues Lina-Marcela Diaz-Gallo, John Castiblanco, Luis M. Gomez, and Aura L. Zapata for contributions. This work was supported by the "Centro Integrado para el Desarrollo de la Investigación (CIDI)," Universidad Pontificia Bolivariana, Medellín (964-11/06-53), and by grants from Fundación TCC, Medellín, School of Medicine, Universidad del Rosario, Bogota, Colombia, and the Fernando Chalem Rheumatology Award to J-MA.

\section{REFERENCES}

1. Naz SM, Symmons DP. Mortality in established rheumatoid arthritis. Best Pract Res Clin Rheum 2007;21:871-83.

2. Solomon DH, Karlson EW, Rimm EB, Cannuscio CC, Mandl LA, Manson JE, et al. Cardiovascular morbidity and mortality in women diagnosed with rheumatoid arthritis. Circulation 2003; 107:1303-7.

3. Meune C, Wahbi K, Assous N, Weber S, Kahan A, Allanore Y. Myocardial dysfunction in rheumatoid arthritis: a controlled tissue-doppler echocardiography study. J Rheumatol 2007;34:2005-9.

4. La Montagna G, Cacciapuoti F, Buono R, Manzella D, Mennillo GA, Arciello A, et al. Insulin resistance is an independent risk factor for atherosclerosis in rheumatoid arthritis. Diab Vasc Dis Res 2007;4:130-5.

5. Chung CP, Oeser A, Solus JF, Avalos I, Gebretsadik T, Shintani 
A, et al. Prevalence of the metabolic syndrome is increased in rheumatoid arthritis and is associated with coronary atherosclerosis. Atherosclerosis 2007 [Epub ahead of print].

6. Gonzalez A, Maradit Kremers H, Crowson CS, Ballman KV, Roger VL, Jacobsen SJ, et al. Do cardiovascular risk factors confer the same risk for cardiovascular outcomes in rheumatoid arthritis patients as in non-RA patients? Ann Rheum Dis 2007 [Epub ahead of print].

7. Jacobsson LT, Turesson C, Hanson RL, Pillemer S, Sievers ML, Pettitt DJ, et al. Joint swelling as a predictor of death from cardiovascular disease in a population study of Pima Indians. Arthritis Rheum 2001;44:1170-6.

8. Glennås A, Kvien TK, Andrup O, Karstensen B, Munthe E. Recent onset arthritis in the elderly: a 5 year longitudinal observational study. J Rheumatol 2000;27:101-8.

9. Lourida ES, Georgiadis AN, Papavasiliou EC, Papathanasiou AI, Drosos AA, Tselepis AD. Patients with early rheumatoid arthritis exhibit elevated autoantibody titers against mildly oxidized low-density lipoprotein and exhibit decreased activity of the lipoprotein-associated phospholipase A2. Arthritis Res Ther 2007;9:R19.

10. Turesson C, McClelland RL, Christianson TJ, Matteson EL. Severe extra-articular disease manifestations are associated with an increased risk of first ever cardiovascular events in patients with rheumatoid arthritis. Ann Rheum Dis 2007;66:70-5.

11. Ross R. Atherosclerosis-an inflammatory disease. N Engl J Med 1999;340:115-26.

12. Shoenfeld Y, Sherer Y, Harats D. Artherosclerosis as an infectious, inflammatory and autoimmune disease. Trends Immunol 2001;22:293-5.

13. Van Doornum S, McColl G, Wicks IP. Accelerated atherosclerosis: an extraarticular feature of rheumatoid arthritis? Arthritis Rheum 2002;46:862-73.

14. Lim TK, Lim E, Dwivedi G, Kooner J, Senior R. Normal value of carotid intima-media thickness- a surrogate marker of atherosclerosis: quantitative assessment by B-mode carotid ultrasound. J Am Soc Echocardiogr 2007 [Epub ahead of print].

15. Park YB, Ahn CW, Choi HK, Lee SH, In BH, Lee HC, et al. Atherosclerosis in rheumatoid arthritis: morphologic evidence obtained by carotid ultrasound. Arthritis Rheum 2002;46:1714-9.

16. Kumeda Y, Inaba M, Goto H, Nagata M, Henmi Y, Furumitsu $\mathrm{Y}$, et al. Increased thickness of the arterial intima-media detected by ultrasonography in patients with rheumatoid arthritis. Arthritis Rheum 2002;46:1489-97.

17. Roman MJ, Moeller E, Davis A, Paget SA, Crow MK, Lockshin $\mathrm{MD}$, et al. Preclinical carotid atherosclerosis in patients with rheumatoid arthritis. Ann Intern Med 2006;144:249-56.

18. Gonzalez-Juanatey C, Llorca J, Testa A, Revuelta J, GarciaPorrua C, Gonzalez-Gay MA. Increased prevalence of severe subclinical atherosclerotic findings in long-term treated rheumatoid arthritis patients without clinically evident atherosclerotic disease. Medicine (Baltimore) 2003;82:407-13.

19. Vaudo G, Marchesi S, Gerli R, Allegrucci R, Giordano A, Siepi $\mathrm{D}$, et al. Endothelial dysfunction in young patients with rheumatoid arthritis and low disease activity. Ann Intern Med 2004; 63:31-5.

20. Dessein PH, Joffe BI, Singh S. Biomarkers of endothelial dysfunction, cardiovascular risk factors and atherosclerosis in rheumatoid arthritis. Arthritis Res Ther 2005;7:R634-43.

21. Anderson TJ, Uehata A, Gerhard MD, Meredith IT, Knab S, Delagrange $\mathrm{D}$, et al. Close relation of endothelial function in the human coronary and peripheral circulations. J Am Coll Cardiol 1995;26:1235-41.

22. Van Doornum S, McColl G, Jenkins A, Green DJ, Wicks IP. Screening for atherosclerosis in patients with rheumatoid arthritis: comparison of two in vivo tests of vascular function. Arthritis Rheum 2003;48:72-80.

23. Gokce N, Keaney JF Jr, Hunter LM, Watkins MT, Menzoian
JO, Vita JA. Risk stratification for postoperative cardiovascular events via noninvasive assessment of endothelial function: a prospective study. Circulation 2002;105:1567-72.

24. Sherer Y, Shoenfeld Y. Mechanisms of disease: atherosclerosis in autoimmune diseases. Nat Clin Pract Rheumatol 2006;2: 99-106.

25. Shoenfeld Y, Gerli R, Doria A, Matsuura E, Cerinic MM, Ronda $\mathrm{N}$, et al. Accelerated atherosclerosis in autoimmune rheumatic diseases. Circulation 2005;112:3337-47.

26. Gonzalez-Gay MA, Gonzalez-Juanatey C, Martin J. Rheumatoid arthritis: a disease associated with accelerated atherogenesis. Semin Arthritis Rheum 2005;35:8-17.

27. Gregersen PK, Silver J, Winchester RJ. The shared epitope hypothesis. An approach to understanding the molecular genetics of susceptibility to rheumatoid arthritis. Arthritis Rheum 1987; 30:1205-13.

28. Gonzalez-Gay MA, Gonzalez-Juanatey C, Ollier WE. Endothelial dysfunction in rheumatoid arthritis: Influence of HLADRB1 alleles. Autoimmun Rev 2004;3:301-4.

29. Gonzalez-Juanatey C, Testa A, Garcia-Castelo A, Garcia-Porrua C, Llorca J, Vidan J, et al. HLA-DRB1 status affects endothelial function in treated patients with rheumatoid arthritis. Am J Med 2003;114:647-52.

30. Gonzalez-Gay MA, Garcia-Porrua C, Hajeer AH. Influence of human leukocyte antigen-DRB1 on the susceptibility and severity of rheumatoid arthritis. Semin Arthritis Rheum 2002;31:355-60.

31. Lee YH, Ji JD, Song GG. Tumor necrosis factor-alpha promoter $-308 \mathrm{~A} / \mathrm{G}$ polymorphism and rheumatoid arthritis susceptibility: a metaanalysis. J Rheumatol 2007;1:43-9.

32. Hajeer AH, Dababneh A, Makki RF, Thomson W, Poulton K, Gonzalez-Gay MA, et al. Different gene loci within the HLA-DR and TNF regions are independently associated with susceptibility and severity in Spanish rheumatoid arthritis patients. Tissue Antigens 2000;55:319-25.

33. Hotamisligil GS, Arner P, Caro JF, Atkinson RL, Spiegelman BM. Increased adipose tissue expression of tumor necrosis factor-alpha in human obesity and insulin resistance. J Clin Invest 1995;95:2409-15.

34. Hürlimann D, Forster A, Noll G, Enseleit F, Chenevard R, Distler $\mathrm{O}$, et al. Anti-tumor necrosis factor-alpha treatment improves endothelial function in patients with rheumatoid arthritis. Circulation 2002;106:2184-7.

35. Gonzalez-Gay MA, De Matias JM, Gonzalez-Juanatey C, Garcia-Porrua C, Sanchez-Andrade A, Martin J, et al. Anti-tumor necrosis factor-alpha blockade improves insulin resistance in patients with rheumatoid arthritis. Clin Exp Rheumatol 2006;24:83-6.

36. Nakamura M, Yoshida H, Arakawa N, Saitoh S, Satoh M, Hiramori K. Effects of tumor necrosis factor-alpha on basal and stimulated endothelium-dependent vasomotion in human resistance vessel. J Cardiovasc Pharmacol 2000;36:487-92.

37. Jaraquemada D, Ollier W, Awad J, Young A, Festenstein H. HLA and rheumatoid arthritis: susceptibility or severity? Dis Markers 1986;4:43-53.

38. Yeap SS, Mohd A, Kumar G, Kong KF, Chow SK, Goh EM, et al. The association between HLA genes and radiological erosions in Malaysian patients with rheumatoid arthritis. Autoimmunity 2007; 40:187-90.

39. Zonana MF, Reyes E, Weisman AK. Coexistence of four autoimmune diseases in one patient: the kaleidoscope of autoimmunity. J Clin Rheumatol 2002;8:322-5.

40. Lorber M, Gershwin ME, Shoenfeld Y. The coexistence of systemic lupus erythematosus with other autoimmune diseases: the kaleidoscope of autoimmunity. Semin Arthritis Rheum 1994; 24:105-13.

41. Anaya JM, Corena R, Castiblanco J, Rojas-Villarraga A, Shoenfeld Y. The kaleidoscope of autoimmunity. multiple autoimmune syn- 
dromes and familial autoimmunity. Exp Rev Clin Immunol 2007;3:623-35.

42. Anaya JM, Gómez L, Castiblanco J. Is there a common genetic basis for autoimmune diseases? Clin Dev Immunol 2006;13:18595.

43. Dessein PH, Norton GR, Woodiwiss AJ, Joffe BI, Wolfe F. Influence of nonclassical cardiovascular risk factors on the accuracy of predicting subclinical atherosclerosis in rheumatoid arthritis. J Rheumatol 2007;34:943-5.

44. Dessein PH, Stanwix AE, Moomal Z. Rheumatoid arthritis and cardiovascular disease may share similar risk factors. Rheumatology (Oxford) 2001;40:703-4.

45. Arnett FC, Edworthy SM, Bloch DA, McShane DJ, Fries JF, Cooper NS, et al. The American Rheumatism Association 1987 revised criteria for the classification of rheumatoid arthritis. Arthritis Rheum 1988;3:315-24.

46. Anaya JM, Tobon GJ, Vega P, Castiblanco J. Autoimmune disease aggregation in families with primary Sjögren's syndrome. J Rheumatol 2006;33:2227-34.

47. Prevoo ML, van't Hof MA, Kuper HH, van Leeuwen MA, van de Putte LB, van Riel PL. Modified disease activity scores that include twenty-eight-joint counts. Development and validation in a prospective longitudinal study of patients with rheumatoid arthritis. Arthritis Rheum 1995;38:44-8.

48. Bruce B, Fries JF. The Stanford Health Assessment Questionnaire: a review of its history, issues, progress, and documentation. J Rheumatol 2003;30:167-78.

49. van Riel PL, van Gestel AM. Clinical outcome measures in rheumatoid arthritis. Ann Rheum Dis 2000;59(Suppl 1):i28-31.

50. Correa PA, Tobón GJ, Citera G, Cadena J, Schneeberger E, Camargo JF, et al. Anti-cyclic citrullinated peptide antibodies in rheumatoid arthritis: relation with clinical features, cytokines and HLA-DRB1. Biomedica 2004;24:140-52.

51. Correa PA, Gomez LM, Cadena J, Anaya JM. Autoimmunity and tuberculosis. Opposite association with TNF polymorphism. J Rheumatol 2005;32:219-24.

52. Anaya JM, Correa PA, Mantilla RD, Arcos-Burgos M. Rheumatoid arthritis association in Colombian population is restricted to HLA-DRB1*04 QRRAA alleles. Genes Immun 2002;3:56-8.

53. Waldron-Lynch F, Adams C, Amos C, Zhu DK, McDermott MF, Shanahan F, et al. Major differences in antigen-processing correlate with a single Arg71 $\leftrightarrow$ Lys substitution in HLA-DR molecules predisposing to rheumatoid arthritis and with their selective interactions with $70-\mathrm{kDa}$ heat shock protein chaperones. J Immunol 2002;169:3015-20.

54. Zanelli E, Gonzalez-Gay MA, David CS. Could HLA-DRB1 be the protective locus in rheumatoid arthritis? Immunol Today 1995;16:274-8.

55. Mattey DL, Dawes PT, Gonzalez-Gay MA, Garcia-Porrua C, Thomson W, Hajeer AH, et al. HLA-DRB1 alleles encoding an aspartic acid at position 70 protect against development of rheumatoid arthritis. J Rheumatol 2001;28:232-9.

56. Khani-Hanjani A, Lacaille D, Horne C, Chalmers A, Hoar DI, Balshaw R, et al. Expression of QK/QR/RRRAA or DERAA motifs at the third hypervariable region of HLA-DRB1 and disease severity in rheumatoid arthritis. J Rheumatol 2002;29:1358-65.

57. van der Helm-van Mil AH, Huizinga TW, Schreuder GM, Breedveld FC, de Vries RR, Toes RE. An independent role of protective HLA class II alleles in rheumatoid arthritis severity and susceptibility. Arthritis Rheum 2005;52:2637-44.

58. Stone NJ, Bilek S, Rosenbaum S. Recent National Cholesterol Education Program Adult Treatment Panel III update: adjustments and options. Am J Cardiol 2005;96:53E-9E.

59. Wilson PW, D’Agostino RB, Levy D, Belanger AM, Silbershatz H, Kannel WB. Prediction of coronary heart disease using risk factor categories. Circulation 1998;97:1837-47.

60. Grundy SM, Pasternak R, Greenland P, Smith S Jr, Fuster V. Assessment of cardiovascular risk by use of multiple-risk-factor assessment equations: a statement for healthcare professionals from the American Heart Association and the American College of Cardiology. Circulation 1999;100:1481-92.

61. Asia Pacific Cohort Studies Collaboration. The impact of cardiovascular risk factors on the age-related excess risk of coronary heart disease. Int J Epidemiol 2006;35:1025-33.

62. Jones DW, Hall JE. Seventh report of the Joint National Committee on Prevention. Detection, evaluation, and treatment of high blood pressure and evidence from new hypertension trials. Hypertension 2004;43:1-3.

63. American Diabetes Association. Diagnosis and classification of Diabetes Mellitus. Diab Care 2004;27:S5-10.

64. Ginsberg HN, Stalenhoef AF. The metabolic syndrome: targeting dyslipidaemia to reduce coronary risk. J Cardiovasc Risk 2003;10:121-8.

65. Roth S, Willcox N, Rzepka R, Mayer MP, Melchers I. Family history of premature coronary heart disease and coronary artery calcification: Multi-Ethnic Study of Atherosclerosis (MESA). Circulation 2007;116:619-26.

66. British Cardiac Society, British Hyperlipidaemia Association, British Hypertension Society, endorsed by the British Diabetic Association. Joint British recommendations on prevention of coronary heart disease in clinical practice. Heart 1998;80(Suppl 2):S1-29.

67. D'Agostino RB, Grundy S, Sullivan LM, Wilson P; CHD Risk Prediction Group. Validation of the Framingham coronary heart disease prediction scores: results of a multiple ethnic groups investigation. JAMA 2001;286:180-7.

68. Liao Y, Kwon S, Shaughnessy S, Wallace P, Hutto A, Jenkins AJ, et al. Critical evaluation of adult treatment panel III criteria in identifying insulin resistance with dyslipidemia. Diabetes Care 2004;27:978-83.

69. Grundy SM, Brewer HB, Cleeman JI, Smith SC, Lenfant C; American Heart Association; National Heart, Lung, and Blood Institute. Definition of metabolic syndrome: report of the $\mathrm{Na}$ tional Heart, Lung, and Blood Institute/American Heart Association conference on scientific issues related to definition. Circulation 2004;109:433-8.

70. Klein S, Allison DB, Heymsfield SB, Kelley DE, Leibel RL, Nonas $\mathrm{C}$, et al. Waist circumference and cardiometabolic risk: a consensus statement from Shaping America's Health: Association for Weight Management and Obesity Prevention; NAASO. The Obesity Society; the American Society for Nutrition; and the American Diabetes Association. Am J Clin Nutr 2007;85:1197-202.

71. Wang Z, Rowley K, Wang Z, Piers L, O’Dea K. Anthropometric indices and their relationship with diabetes, hypertension and dyslipidemia in Australian Aboriginal people and Torres Strait Islanders. Eur J Cardiovasc Prev Rehabil 2007;14:172-8.

72. D'Agostino RB Sr, Grundy S, Sullivan LM, Wilson P, CHD Risk Prediction Group. Metabolic syndrome, or What you will: definitions and epidemiology. Diab Vasc Dis Res 2007; 4:32-8.

73. Wendelhag I, Wiklund O, Wikstrand J. Arterial wall thickness in familial hypercholesterolemia. Ultrasound measurement of intima-media thickness in the common carotid artery. Arterioscler Thromb 1992;12:70-7.

74. Salonen R, Salonen JT. Determinants of carotid intima-media thickness: a population-based ultrasonography study in eastern Finnish men. J Intern Med 1991;229:225-31.

75. Pignoli P, Tremoli E, Poli A, Oreste P, Paoletti R. Intimal plus medial thickness of the arterial wall: a direct measurement with ultrasound imaging. Circulation 1986;74:1399-406.

76. Mancia G, De Backer G, Dominiczak A, Cifkova R, Fagard R, Germano G, et al. 2007 Guidelines for the Management of Arterial Hypertension: The Task Force for the Management of Arterial Hypertension of the European Society of Hypertension (ESH) and of the European Society of Cardiology (ESC). J Hy- 
pertens 2007;25:1105-87. Erratum in: J Hypertens 2007;25: 1749.

77. Lambert J, Stehouwer CD. Modulation of endothelium-dependent, flow-mediated dilatation of the brachial artery by sex and menstrual cycle. Circulation 1996;94:2319-20.

78. Corretti MC, Anderson TJ, Benjamin EJ, Celermajer D, Charbonneau F, Creager MA, et al. Guidelines for the ultrasound assessment of endothelial-dependent flow-mediated vasodilation of the brachial artery: a report of the International Brachial Artery Reactivity Task Force. J Am Coll Cardiol 2002;39:257-65.

79. Yeboah J, Burke GL, Crouse JR, Herrington DM. Relationship between brachial flow-mediated dilation and carotid intima-media thickness in an elderly cohort: The Cardiovascular Health Study. Atherosclerosis 2007 [Epub ahead of print].

80. Accini JL, Sotomayor A, Trujillo F, Barrera JG, Bautista L, López-Jaramillo P. Colombian study to assess the use of noninvasive determination of endothelium-mediated vasodilatation (CANDEV). Normal values and factors associated. Endothelium 2001;2:157-66.

81. Tsimikas S, Brilakis ES, Miller ER, McConnell JP, Lennon RJ, Kornman KS, et al. Oxidized phospholipids, Lp(a) lipoprotein, and coronary artery disease. N Engl J Med 2005;353:46-57.

82. Le NA, Walter MF. The role of hypertriglyceridemia in atherosclerosis. Curr Atheroscler Rep 2007;9:110-5.

83. Georgiadis AN, Papavasiliou EC, Lourida ES, Alamanos Y, Kostara C, Tselepis AD, et al. Atherogenic lipid profile is a feature characteristic of patients with early rheumatoid arthritis: effect of early treatment - a prospective, controlled study. Arthritis Res Ther 2006;8:R82.

84. Edwards CJ, Syddall H, Goswami R, Goswami P, Dennison EM, Arden NK, et al. The autoantibody rheumatoid factor may be an independent risk factor for ischaemic heart disease in men. Heart 2007;93:1263-7.

85. Turesson C, Jacobsson LT, Sturfelt G, Matteson EL, Mathsson L, Rönnelid J. Rheumatoid factor and antibodies to cyclic citrullinated peptides are associated with severe extra-articular manifestations in rheumatoid arthritis. Ann Rheum Dis 2007;66:59-64.

86. van Gaalen FA. Testing for antibodies to cyclic citrullinated peptides and rheumatoid factor-what is best for early RA? Nat Clin Pract Rheumatol 2007;3:488-9.

87. Day C. Adipose tissue as an immunological organ: toll-like receptors C1q/TNFs and CTRPs. Trends Immunol 2007;28:393-9.

88. del Rincón ID, Williams K, Stern MP, Freeman GL, Escalante A. High incidence of cardiovascular events in a rheumatoid arthritis cohort not explained by traditional cardiac risk factors. Arthritis Rheum 2001;44:2737-45.

89. Ljung L, Olsson T, Engstrand S, Wållberg-Jonsson S, Söderberg S, Rantapää-Dahlqvist S. Utility of the Framingham risk score to predict the presence of coronary atherosclerosis in patients with rheumatoid arthritis. Arthritis Res Ther 2006;8:R186.

90. Del Rincón, O'leary DH, Freeman GL, Escalante A. Increased coronary-artery atherosclerosis in rheumatoid arthritis: relationship to disease duration and cardiovascular risk factors. Arthritis Rheum 2005;52:3045-53.

91. Delgado-Vega AM, Anaya JM. Meta-analysis of HLA-DRB1 polymorphism in Latin American patients with rheumatoid arthritis. Autoimmun Rev 2007;6:402-8.

92. Gonzalez-Gay MA, Gonzalez-Juanatey C, Lopez-Diaz MJ, Piñeiro A, Garcia-Porrua C, Miranda-Filloy JA, et al. HLADRB1 and persistent chronic inflammation contribute to cardiovascular events and cardiovascular mortality in patients with rheumatoid arthritis. Arthritis Rheum 2007;57:125-32.

93. Gerli R, Sherer Y, Vaudo G, Schillaci G, Gilburd B, Giordano A, et al. Early atherosclerosis in rheumatoid arthritis: effects of smoking on thickness of the carotid artery intima media. Ann NY Acad Sci 2005;1051:281-90.

94. Chung CP, Oeser A, Raggi P, Gebretsadik T, Shintani AK, Sokka $\mathrm{T}$, et al. Increased coronary-artery atherosclerosis in rheu- matoid arthritis: relationship to disease duration and cardiovascular risk factors. Arthritis Rheum 2005;52:3045-53.

95. Emery P, Lugmani R. The validity of surrogate markers in rheumatic disease. Br J Rheumatol 1993;32:S3-8.

96. Koenig W, Sund M, Fröhlich M, Fischer HG, Löwel H, Döring A, et al. C-Reactive protein, a sensitive marker of inflammation, predicts future risk of coronary heart disease in initially healthy middle-aged men: results from the MONICA (Monitoring Trends and Determinants in Cardiovascular Disease) Augsburg Cohort Study, 1984 to 1992. Circulation 1999;99:237-42.

97. Pearson TA, Mensah GA, Alexander RW, Anderson JL, Cannon RO 3rd, Criqui M, et al. Markers of inflammation and cardiovascular disease: application to clinical and public health practice: a statement for healthcare professionals from the Centers for Disease Control and Prevention and the American Heart Association. Circulation 2003;107:499-511.

98. Del Rincón I, Williams K, Stern MP, Freeman GL, O’Leary $\mathrm{DH}$, Escalante A. Association between carotid atherosclerosis and markers of inflammation in rheumatoid arthritis patients and healthy subjects. Arthritis Rheum 2003;48:1833-40.

99. Hwang SJ, Ballantyne CM, Sharrett AR, Smith LC, Davis CE, Gotto AM Jr, et al. Circulating adhesion molecules VCAM-1. ICAM-1, and E-selectin in carotid atherosclerosis and incident coronary heart disease cases: the Atherosclerosis Risk In Communities (ARIC) study. Circulation 1997;96:4219-25.

100. Ridker PM, Hennekens CH, Roitman-Johnson B, Stampfer MJ, Allen J. Plasma concentration of soluble intercellular adhesion molecule 1 and risks of future myocardial infarction in apparently healthy men. Lancet 1998;351:88-92.

101. Ridker PM, Buring JE, Rifai N. Soluble P-selectin and the risk of future cardiovascular events. Circulation 2001;103:491-5.

102. Roivainen M, Viik-Kajander M, Palosuo T, Toivanen P, Leinonen M, Saikku P, et al. Infections, inflammation, and the risk of coronary heart disease. Circulation 2000;101:252-7.

103. Gonzalez-Gay MA, Gonzalez-Juanatey C, Piñeiro A, GarciaPorrua C, Testa A, Llorca J. High-grade C-reactive protein elevation correlates with accelerated atherogenesis in patients with rheumatoid arthritis. J Rheumatol 2005;32:1219-23.

104. Sattar N, McCarey DW, Capell H, McInnes IB. Explaining how "high-grade" systemic inflammation accelerates vascular risk in rheumatoid arthritis. Circulation 2003;108:2957-63.

105. Abou-Raya A, Abou-Raya S. Inflammation: a pivotal link between autoimmune diseases and atherosclerosis. Autoimmun Rev 2006;5:331-7.

106. Marenberg ME, Risch N, Berkman LF, Floderus B, de Faire U. Genetic susceptibility to death from coronary heart disease in a study of twins. N Engl J Med 1994;330:1041-6.

107. Fischer M, Broeckel U, Holmer S, Baessler A, Hengstenberg C, Mayer B, et al. Distinct heritable patterns of angiographic coronary artery disease in families with myocardial infarction. Circulation 2005;111:855-62.

108. Nsengimana J, Samani NJ, Hall AS, Balmforth AJ, Mangino M, Yuldasheva N, et al. Enhanced linkage of a locus on chromosome 2 to premature coronary artery disease in the absence of hypercholesterolemia. Eur J Hum Genet 2007;15:313-9.

109. Qiao JH, Castellani LW, Fishbein MC, Lusis AJ. Immune-complex-mediated vasculitis increases coronary artery lipid accumulation in autoimmune-prone MRL mice. Arterioscler Thromb 1993; 13:932-43.

110. Szalai C, Füst G, Duba J, Kramer J, Romics L, Prohászka Z, et al. Association of polymorphisms and allelic combinations in the tumour necrosis factor-alpha-complement $\mathrm{MHC}$ region with coronary artery disease. J Med Genet 2002;39:46-51.

111. Samani NJ, Erdmann J, Hall AS, Hengstenberg C, Mangino M, Mayer B, et al. Genomewide association analysis of coronary artery disease. N Engl J Med 2007;357:443-53. 
112. Broeckel U, Hengstenberg C, Mayer B, Holmer S, Martin LJ, Comuzzie AG, et al. A comprehensive linkage analysis for myocardial infarction and its related risk factors. Nat Genet 2002; 30:210-4.

113. Somers EC, Thomas SL, Smeeth L, Hall AJ. Autoimmune diseases co-occurring within individuals and within families: a systematic review. Epidemiology 2006;17:202-17.

114. Eroglu GE, Kohler PF. Familial systemic lupus erythematosus: the role of genetic and environmental factors. Ann Rheum Dis 2002;61:29-31.

115. Björnådal L, Brandt L, Klareskog L, Askling J. Impact of parental history on patients' cardiovascular mortality in rheumatoid arthritis. Ann Rheum Dis 2006;65:741-5.

116. Pineda-Tamayo R, Arcila G, Restrepo P, Anaya JM. Impact of cardiovascular illness on hospitalization costs in patients with rheumatoid arthritis. Biomedica 2004;4:366-74. 